\title{
An antioxidant role for calcium antagonists in the prevention of adrenaline mediated myocardial and endothelial damage
}

\author{
Alberto A Noronha-Dutra, Elinor M Steen-Dutra, Neville Woolf
}

\begin{abstract}
Objective-To investigate the mechanism of calcium antagonist mediated cytoprotection against the damaging effects of adrenaline in vivo on cardiac myocytes and human endothelial cells from the umbilical vein.
\end{abstract}

Methods-Human endothelial cells cultured from the umbilical vein and isolated rat cardiac myocytes were treated with plasma from rats given adrenaline 30 minutes previously with pretreatment with calcium antagonists and without. The effect on indices of cell damage that suggest oxidation stress was determined.

Results-Pretreatment of rats with calcium antagonists before adrenaline administration largely inhibited the cytotoxic effects of their plasma on the two target cells used. Plasma taken from animals not pretreated with calcium antagonists caused release of oxidised glutathione from cells, a fall in intracellular reduced glutathione concentration, a fall in ATP production, and release of angiotensin converting enzyme from the endothelial cells.

Conclusion-Calcium antagonists protect against the cardiotoxic effects of catecholamine by preventing the generation of plasma borne cytotoxic compounds, which are probably free radicals.

The calcium channel blockers have an established role in clinical practice related to their effect on smooth muscle contractility. Evidence suggests that other functions of this class of drug are likely to be of equal interest. Many of the calcium antagonists inhibit the formation of atherosclerosis, and cause its regression in hyperlipidaemic animal models. Verapamil inhibited cataract formation in alloxan-diabetic rats in a tissue where there are no vascular smooth muscle cells. ${ }^{2}$ Methoxy-verapamil inhibited the myocardial injury produced by injection of catecholamines. ${ }^{3}$ The mechanism by which calcium channel blockers confer this myocardial protection is not certain. The initial hypothesis was that calcium influx into the myocyte would deplete the intracellular pool of adenosine triphosphate thus provoking an energy collapse and leading to cell death. ${ }^{45}$ Blockage of the calcium channels should therefore prevent this depletion of adenosine triphosphate. This hypothesis is inconsistent with the fact that adenosine triphosphate depletion does not cause myocardial damage. ${ }^{6}$ When isolated rat cardiomyocytes maintained in a medium with a high calcium concentration were treated with isoprenaline or the calcium ionophore $A$ 23187 there was only a transient effect on ATP production. ${ }^{78}$ It is possible ${ }^{910}$ that the damage produced in the myocardium by adrenaline or isoprenaline is mediated by free radicals. This hypothesis arose from the observation that catecholamines had no direct effect on cardiac myocytes maintained in vitro ${ }^{4}$ whereas plasma taken from rats 30 minutes after injection of adrenaline was profoundly cytotoxic to these cells. $^{10}$

We studied the effect of calcium blockers on the oxidative stress-mediated cytotoxicity of plasma from catecholamine treated animals. The calcium blockers chosen were methoxyverapamil (D600) and nifedipine, which belong to the phenethylamine and the dihydropiridine groups of calcium antagonists respectively. The effects of each of these in the same model system would show whether these chemically different compounds have a common mode of action in inhibiting catecholamine induced myocardial injury.

Glutathione is the main source of reducing equivalents for protecting the cell against oxidative stress and the main cellular mechanisms for protection against free radical attack are the glutathione peroxidases and glutathione transferase. ${ }^{11-13}$ Cells under oxidative stress extrude oxidised glutathione ${ }^{1314}$ and the amount of glutathione extruded is proportional to the degree of oxidative stress. Thus oxidative stress tends to reduce the concentration of intracellular oxidised glutathione ${ }^{15}$ and the extent of the decline in the ratio of intracellular reduced glutathione to extracellular oxidised glutathione provides a measure of the degree of oxidative stress imposed on the cells.

To determine the degree of cell damage in each experiment we measured two variables: release into the supernatant of the membrane bound angiotensin converting enzyme from human endothelial cells cultured from the umbilical vein and ATP production, measured in both endothelial cells and in isolated rat cardiomyocytes.

To make these stressed cells more susceptible to damage by free radicals the concentration of glucose in the incubating medium during the experiments was reduced. An increase in oxidised glutathione activates the pentose phosphate pathway. This is one of the 
main sources of the reduced NADP (NADPH) that is used to regenerate reduced glutathione.

\section{Methods}

Endothelial cells derived from umbilical cord veins were established in culture by modifications of the method originally described by Jaffe et al. ${ }^{16}$ The cells were obtained by digestion with a $0.07 \%$ solution of collagenase (type 1 CLS Clostridium histolyticum, Worthington) for 20 minutes. The cells were resuspended in medium M199 supplemented with $20 \%$ fetal calf serum (Flow), with penicillin $(100 \mu \mathrm{g} / \mathrm{ml})$, streptomycin $(100 \mu \mathrm{g} / \mathrm{ml})$, and amphotericin B $(25 \mu \mathrm{g} / \mathrm{ml})$. We used first passage cells grown on Thermanox coverslips $(13 \mathrm{~mm})$ in the experiments.

Cardiomyocytes were prepared from male Sprague-Dawley rats with an average weight of $280 \mathrm{~g}$ by a modified Powell and Twist technique. ${ }^{17}$ The heart was preperfused with calcium free Krebs's bicarbonate ( $\mathrm{pH} \mathrm{7.4)}$ containing $0.5 \mathrm{mg} / \mathrm{dl}$ of nitroprusside until it was clear of blood, and a $10 \mathrm{mmol} / 1$ solution of HEPES and superoxide dismutase (25 units/ $\mathrm{ml}$ ) was added to the perfusion medium.

The cells were treated with plasma obtained from rats injected 30 minutes previously with adrenaline bitartrate (Sigma) at a dose of $5 \mathrm{mg} / \mathrm{kg}$. Rats were also pretreated with $3 \mathrm{mg} / \mathrm{kg}$ of methoxyverapamil or $2 \mathrm{mg} / \mathrm{kg}$ of nifedipine (Sigma) one minute before being injected with adrenaline. In the experiments with myocytes the cells were incubated for 30 minutes with the plasma. The plasma was then removed and the cells were incubated with Krebs's bicarbonate medium in which glucose was replaced by sucrose. The endothelial cells, after incubation with plasma for 30 minutes, were incubated in Hanks's medium with $5 \%$ fetal calf serum in which glucose was again replaced by sucrose.

\section{GLUTATHIONE MEASUREMENT}

Reduced glutathione was measured in myocytes according to the method described by Noronha-Dutra et al. ${ }^{10}$ Total glutathione, released by the cells, was measured in the supernatant after the protein was precipitated with $4 \%$ sulphosalicyclic acid containing EDTA $(2 \mathrm{mmol} / \mathrm{l})$ and the extracts were neutralised with triethanolamine (diluted 1:5 in water). Glutathione was then estimated by measuring the formation of 5-thio-2-nitrobenzoate at $412 \mathrm{~nm}$ with a LKB Ultrospec 4050 spectrophotometer. ${ }^{18}$

The total glutathione in the rat plasma, as measured before the addition of the plasma to the cells, was subtracted from the value for the released glutathione.

\section{ANGIOTENSIN CONVERTING ENZYME ASSAY}

Angiotensin converting enzyme was measured in the supernatant from endothelial cells by a fluorimetric assay. ${ }^{19}$ Angiotensin converting enzyme was also measured in the rat plasma before it was added to the cells and this value was subtracted from the concentration found in the supernatant.

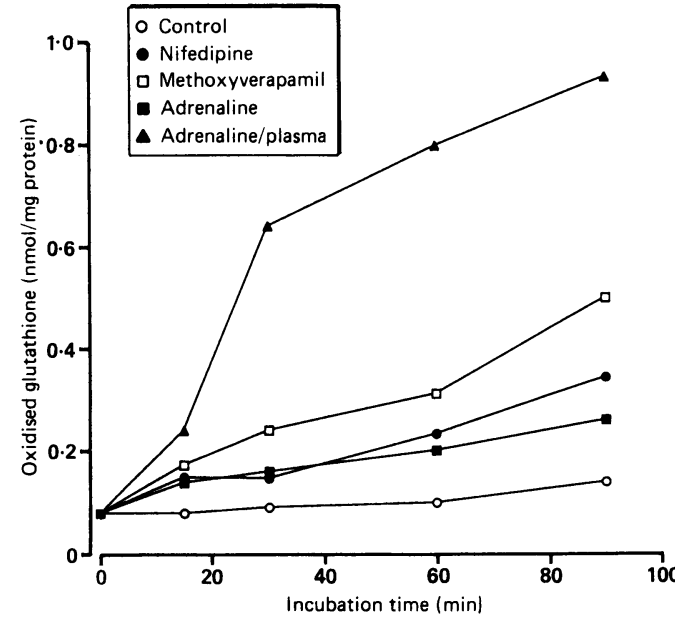

Figure 1 Inhibition of release of oxidised glutathione from isolated rat cardiac myocytes exposed to "adrenaline plasma" from animals pretreated with calcium antagonists.

ATP MEASUREMENT

ATP concentrations were measured both in endothelial cells and myocytes, after freezing and thawing the cells twice, in an LKB-Wallac luminometer by the bioluminescent luciferinluciferase method.

\section{PROTEIN MEASUREMENT}

Protein was measured by the method of Rosebary. ${ }^{20}$ All the experiments were repeated at least twice and were performed in duplicate. The figures show the mean of this experiment.

\section{Results}

\section{SECRETED GLUTATHIONE}

Treatment of isolated cardiomyocytes with plasma taken from animals given catecholamine considerably increased the secretion of glutathione. The increase started about 15 minutes after the plasma was added to the cells' incubating medium (fig 1). The removal of the plasma containing medium from the cells and its replacement by fresh incubating medium had no effect on the extracellular accumulation of secreted glutathione which continued. This

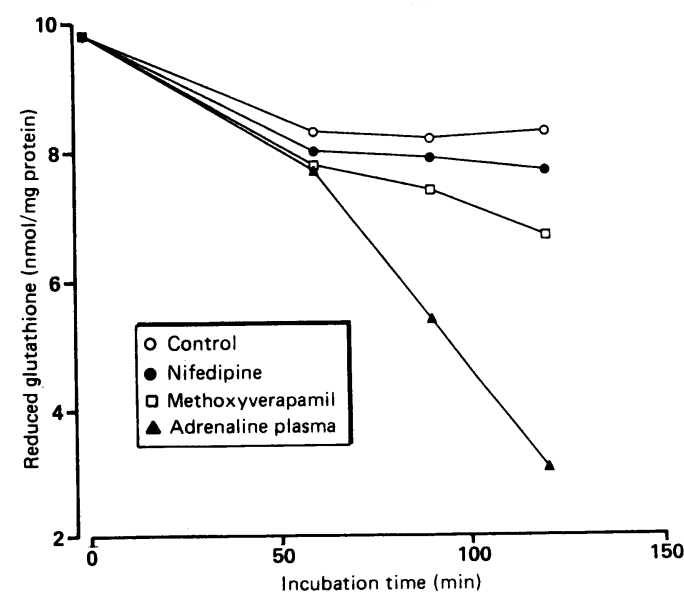

Figure 2 Inhibition of decrease in intracellular reduced glutathione in rat cardiac myocytes exposed to "adrenaline plasma" from animals pretreated with calcium antagonists. 
Figure 3 Calcium antagonists inhibit the fall in $A T P$ production by cardiac myocytes $(A)$ and human umbilical vein endothelial cells (B).
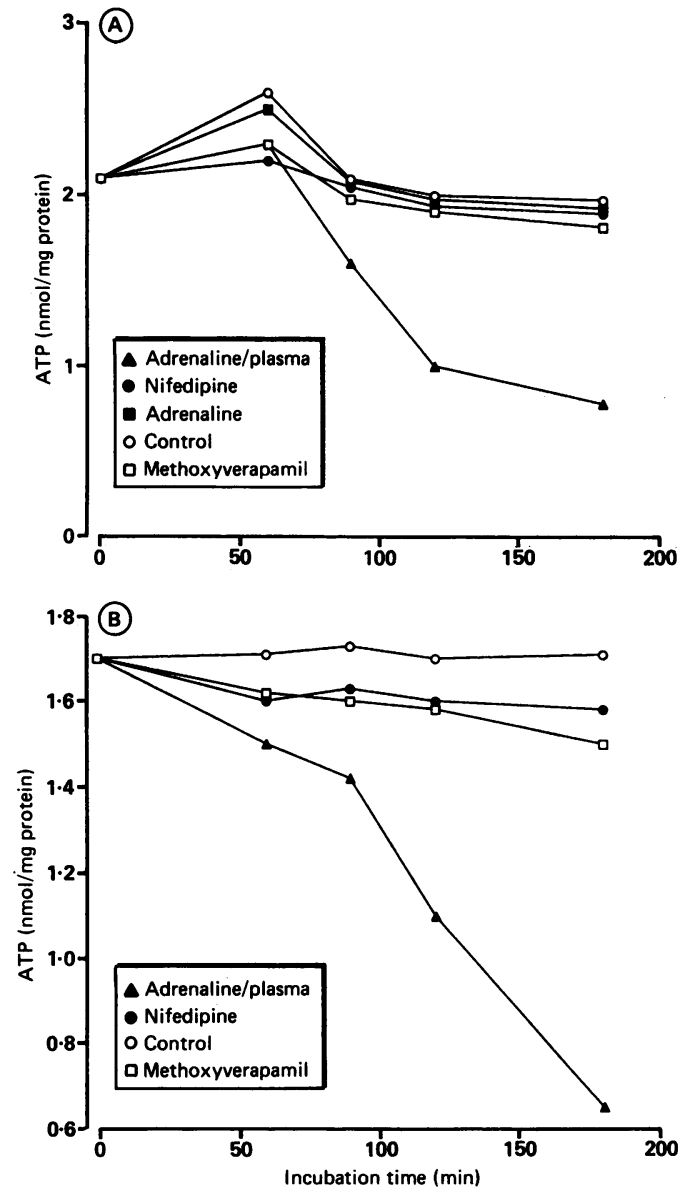

suggests that the initial cell injury caused by the plasma from animals treated with adrenaline was irreversible.

The release of glutathione from the cells and
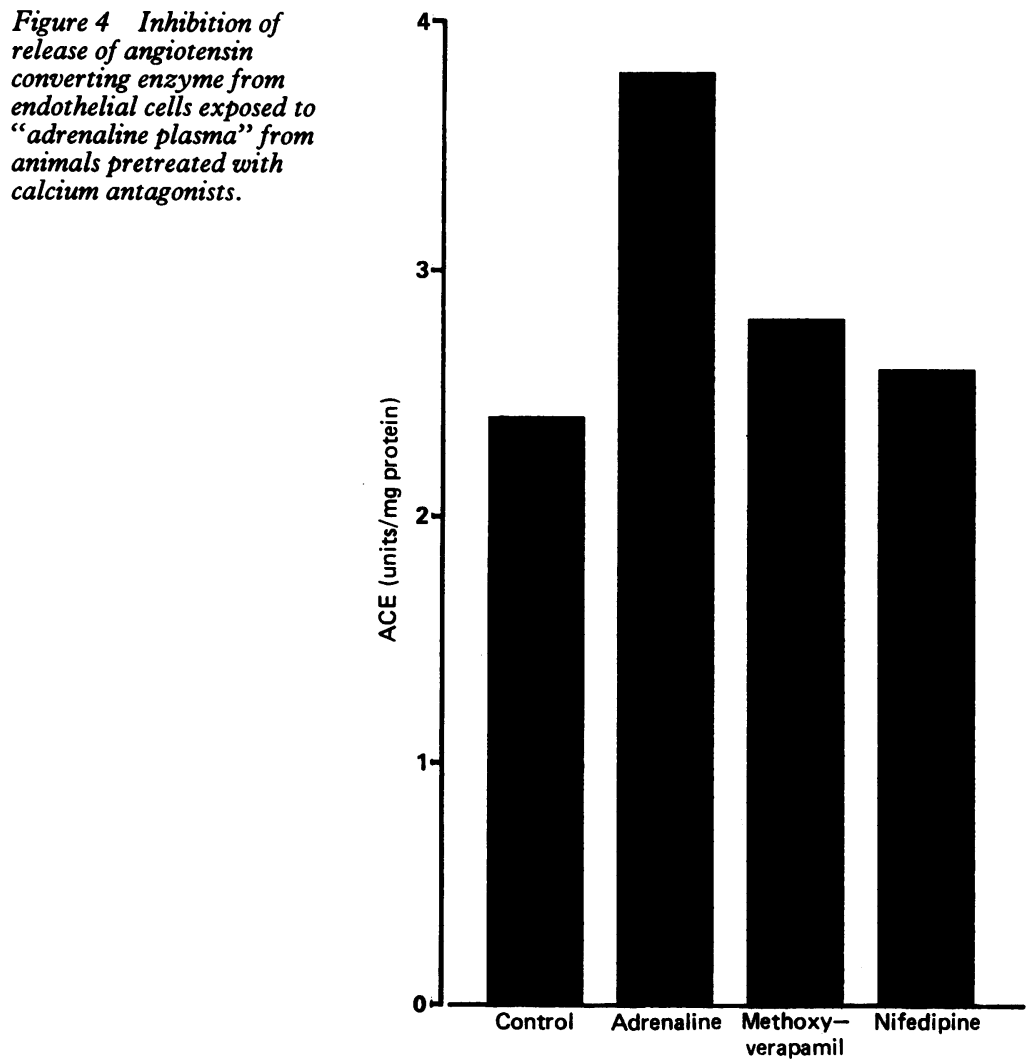

by implication the degree of oxidative stress was clearly reduced by treatment with the calcium blockers.

\section{REDUCED GLUTATHIONE}

The concentration of reduced glutathione in myocytes was greatly decreased by the treatment with the plasma from animals pretreated with adrenaline (fig 2). In endothelial cells calcium blockers were also effective in preventing the oxidation of glutathione.

\section{ADENOSINE TRIPHOSPHATE MEASUREMENT}

The fall in adenosine triphosphate after the treatment of the cells shows that endothelial cells are more susceptible than cardiomyocytes to the toxic effect of the plasma derived from animals pre-dosed with adrenaline (fig $3 \mathrm{~A}$ and B). But in both cells the fall in adenosine triphosphate was prevented by the calcium blockers.

\section{ANGIOTENSIN CONVERTING ENZYME}

When endothelial cells were treated with plasma taken from animals given adrenaline the concentration of angiotensin converting enzyme, which is localised in the outer part of the plasma membrane of the cells, did not increase in the incubating enzyme if the cells were treated with plasma from animals that had been pre-dosed with calcium blockers before they were given adrenaline (fig 4).

\section{Discussion}

Hitherto the best evidence linking calcium antagonists with protection against cardiac injury mediated by free radicals relates to the protection they confer against the damage induced by doxorubicin, ${ }^{21}$ where the role of free radicals in the injury is well established. There is evidence from other published reports that calcium antagonists can act as antioxidants. ${ }^{22-24}$

The evidence we present provides further confirmation that adrenaline damage to cardiac myocytes is largely caused by oxidative stress. More importantly it also shows that calcium antagonists largely prevent this stress. Much less glutathione was lost from cells when that plasma came from animals pretreated with calcium blockers. The cytotoxicity of "adrenaline plasma" could not be reproduced when adrenaline was added (in vitro) to the plasma of control (untreated) animals, even at concentrations up to one hundred times higher than would be expected to be found normally in rat plasma.

The protective effect of calcium antagonists in this study was obtained not by treatment of the target cells themselves but by pretreating the animals from which the "adrenaline plasma" was derived. These results suggest therefore that in this model calcium antagonists act by preventing the generation in vivo of the cytotoxic plasma borne compounds that result from the administration of adrenaline.

A role for calcium antagonists in inhibiting the generation of free radicals might serve to protect native low density lipoprotein within the arterial intima from undergoing the 
oxidative modification that seems to be important in the development of atherosclerotic lesions. ${ }^{25}$ This might be an explanation for the inhibition of new lesion formation that has been described in animals and now in humans. ${ }^{26-28}$ Equally, calcium antagonists may prevent endothelial damage and thus influence the progression of atherosclerosis.

1 Henry P. Calcium antagonists as antiatherogenic agents. Ann NY Acad Sci 1988;522:411-9.

2 Fleckenstein A. Calcium antagonism in heart and smooth muscle. Experimental facts and therapeutic prospects. New York: John Wiley \& Sons, 1983:280-5.

3 Steen EM, Woolf N, Powell T, Rowles PM. The effect of a calcium antagonist (D 600) on isoprenaline induced myocardial necrosis in the rat. Br J Exp Pathol 1979, 60:335-9.

4 Fleckenstein A. Specific inhibitors and promoters of calcium action in the excitation-contraction coupling of heart action in the excitation-contraction coupling of heart
muscle and their role in the prevention of production of muscle and their role in the prevention of production of cardiac lesions. In: Harris P, Opie LH, eds. Calcium

5 Fleckenstein A, Janke J, Doring HL, Leder O. Myocardial fiber necrosis due to intracellular $\mathrm{Ca}-$ overload $-\mathrm{a}$ new principle in cardiac physiology. In: Dhalla NS, ed. Recent advances in studies in cardiac structures and metabolism. Myocardial biology vol 4. Baltimore: University Park Press, 1974:536-41.

6 Jennings RB, Reimer KA, Stennbergen C Jr, Schaper J. Total ischaemia III: Effect of inhibition of anaerobic glycolysis. J Mol Cell Cardiol 1989;21(suppl I):37-54.

7 Noronha-Dutra AA, Steen EM. The effect of isoproterenol and propanolol on ATP levels of isolated cardiac myocytes [Abstract]. J Pathol 1982:134:311.

8 Steen EM, Noronha-Dutra AA, Woolf N. The response of isolated heart cells to cardiotoxic concentrations of isoproterenol. J Pathol 1982;137:167-76.

9 Noronha-Dutra AA, Steen EM, Woolf N. The correlation between catecholamine and lipid peroxidation induced between catecholamine and lipid peroxidation induced Adult heart muscle cells. Darmstadt: Steinkopf Verlag, Adult heart

10 Noronha-Dutra AA, Steen EM, Woolf N. Epinephrineinduced cytotoxicity of rat plasma. Lab Invest 1988; 59:817-23.

11 Singal PK, Beamish RE, Dhala NS. Potential oxidative pathways of catecholamines in the formation of lipid peroxides and genesis of heart disease. Adv Exp Med Biol 1983;161:391-5.

12 Sies H. Oxidative stress. In: Sies H, eds. Oxidative stress. London: Academic Press, 1985:1-8.
13 Reed DJ. Regulation of oxidative process by glutathione. Biochem Pharmacol 1986;35:7-13.

14 Tan KH, Meyer DJ, Belin J, Ketterer B. Inhibition of microsomal lipid peroxidation by glutathione and glutathione transferases B and AA. Biochem J 1984;220:243-52.

15 Adams AJ, Lautterburg BH, Mitchell JR. Plasma glutathione and disulpide in the rat: regulation and response to thione and disulpide in the rat: regulation and response to

16 Jaffe EA, Nachman RL, Becker CG, Minick CR. Culture of human endothelial cells derived from umbilical veins. human endothelial cells derived from umbilical veins. Identification of morphologic

17 Powell P, Twist VW. A rapid technique for the isolation and purification of adult cardiac muscle cells having respiratory control and a tolerance to calcium. Biochem Biophys Res Commun 1976;72:327-34.

18 Akerboom PM, Sies H. Assay of glutathione, glutathione disulfide, and glutathione mixed disulfides in biological samples. Methods Enzymol 1981;77:373-6.

19 Friedland J, Silverstein E. A sensitive assay for serum angiotensin-converting enzyme. Am J Clin Pathol 1976; 66:416-24.

20 Rosebery AL. Protein measurement with folin/phenol reagent. J Biol Chem 1953;193:265-72.

21 Milei J, Vazquez A, Boveris A, et al. The role of prenylamine in the prevention of adriamycin-induced cardiotoxicity. A review of experimental and clinical findings. J Int Med Res 1988; 16:19-30

22 Kobayashi A, Yamashita $T$, Kaneko $M$, Hayashi $H$, Yamazaki N. Effect of verapamil on experimental cardiopathy in the Syrian hamster. J Am Coll Cardiol 1987;10:1128-38

23 Kaneko M, Lee SL, Wolf CM, Dhalla NS. Reduction of calcium channel antagonist binding sites by oxygen free radicals in rat heart. J Mol Cell Cardiol 1989;21:935-43.

24 Ondrias K, Misik V, Gergel D, Stasko A. Lipid peroxidation of phosphatidylcholine liposomes depressed by the calcium channel blockers nifedipine and verapamil and by the antiarrhythmic-antihypoxic drug stobadine. Biochim Biophys Acta 1989;1003:238-45.

25 Steinberg D, Parthasarathy S, Carew T, Khoo J, Witzum J. Beyond cholesterol. Modifications of low-density lipoprotein that increases its atherogenicity. $N$ Engl J Med 1989;320:915-24.

26 Loaldi A, Polese A, Montorsi P, et al. Comparison of nifedipine, propanolol and isosorbide dinitrate on angiographic progression and regression of coronary angiographic progression and regression of coronary arterial narrowing

27 Lichtlen PR, Hugenholtz PG, Rafflenheul W, Herker H, Jost $S$, Deckers JP. Retardation of the angiographic progression of coronary artery disease in man by the calcium channel blocker nifedipine. Results of the International Nifedipine Trial on Antiotherosclerotic Therapy (INTACT). Lancet 1990;i:1109-13.

28 Waters D, Lesperance J, Theroux $\mathrm{P}$, et al. A controlled clinical trial to assess the effect of a calcium channel blocker on the progression of coronary atherosclerosis. Circulation 1990;82:1940-53. 